América sin Nombre, n. ${ }^{\circ} 24$ (2020): 35-48

DOI 10.14198/AMESN.2020.24-2.03

ISSN: 1577.3442 / eISSN: 1989-9831

Fecha de recepción: 04/06/2018

Fecha de aceptación: 29/11/2018
Modo de citación de este artículo:

Delgado Del Aguila, Jesús Miguel. «Taxonomía metafórica en La estación violenta (1958), orientación retórica hacia la interpretación progresista de la humanidad». La nueva novela latinoamericana sin limites. Lise Segas y Félix Terrones (coordinadores). América sin Nombre, 24 (2020): 35-48, DOI: 10.14198/AMESN.2020.24-2.03

Link para este artículo: http://dx.doi.org/10.14198/AMESN.2020.24-2.03

\title{
Taxonomía metafórica en La estación violenta (1958), orientación retórica hacia la interpretación progresista de la humanidad
}

\author{
Metaphorical taxonomy in La estación violenta (1958), rhetorical orientation towards \\ the progressive interpretation of humanity
}

\author{
Jesús Miguel Delgado Del Aguila* \\ Universidad Tecnológica del Perú
}

\begin{abstract}
Resumen
Este artículo toma como referencia los poemas «¿No hay salida?» y «El río» de La estación violenta (1958), para demostrar que esta obra literaria inserta el pensamiento reflexivo de que la humanidad debe priorizar sus proyectos personales, preservarlos y desarrollarlos en medida de lo posible. Esta orientación ideológica del autor será comprobada a través de la interpretación retórica de este objeto de análisis, que es válida desde la taxonomía de los tipos de metáfora. Esta propuesta teórica fue formulada por George Lakoff y Mark Johnson en su libro Metáforas de la vida cotidiana (1995) y ha sido estudiada rigurosamente por el investigador Camilo Fernández Cozman. Entre sus planteamientos, el que se empleará es el que busca la distinción y la articulación de megametáforas (nociones generales que, a la vez, conforman las metáforas orientacionales, ontológicas y estructurales) y metáforas específicas (nociones particulares que se derivan de las megametáforas). Este trabajo tiene la finalidad de que se argumente con propiedad epistemológica el quehacer literario del escritor mexicano Octavio Paz. De la misma manera, se confrontan los conceptos de interlocutores y cosmovisión como respaldo para afianzar esa peculiar direccionalidad ideológica del poemario.
\end{abstract}

Palabras clave: análisis de poemas, emparejamiento metafórico, megametáfora, tipología de metáforas, interlocutores, cosmovisión

\section{Abstract}

This paper takes as reference the poems «No Exit?» and «The River» from The Violent Station (1958), to demonstrate that this literary work inserts the reflective thought that humanity must prioritize their personal projects, preserve them and develop them in as much as possible. This ideological orientation of the author will be verified through the rhetorical interpretation of this object of analysis, which is valid from the taxonomy of the types of metaphor. This theoretical proposal was formulated by George Lakoff and Mark Johnson in his book Metaphors We Live By (1995) and has been

* Docente e investigador en la Universidad Tecnológica del Perú. Asimismo, cuenta con el grado académico de licenciado y doctorando en Literatura Peruana y Latinoamericana de la Universidad Nacional Mayor de San Marcos (Lima, Perú). Tiene intereses culturales y literarios en la parte teórica que permiten el análisis de las obras literarias latinoamericanas. Su tesis de licenciatura titulada Protagonismo violento y modos de representación en La ciudady los perros (1963) se publicó el 2017. Actualmente, se encuentra investigando referentes para estudiar las novelas de Mario Vargas Llosa y el ensayo El laberinto de la soledad (1950) de Octavio Paz. 
rigorously studied by researcher Camilo Fernandez Cozman. Among its approaches, the one that will be used is the one that seeks the distinction and articulation between megametaphors (general notions that, at the same time, conform the orientational, ontological and structural metaphors) and specific metaphors (particular notions that derive from megametaphors). This work has the purpose of arguing with epistemological property the literary work of the Mexican writer Octavio Paz. In the same way, the concepts of interlocutors and worldview are confronted as support to strengthen this peculiar ideological directionality of the poems.

Keywords: analysis of poems, metaphorical pairing, megametaphor, typology of metaphors, interlocutors, worldview

\section{Introducción}

El poemario La estación violenta (1958) fue escrito por el escritor mexicano Octavio Paz. Este libro contiene nueve poemas extensos y de una temática que abarca el conflicto temporal entre el ser y la comunidad. Todo ello se desarrolla con el fin de revertir el orden imperante de la sociedad, aunque de una manera particular: con la oposición de lo tradicional. Estos se intitulan «Himno entre ruinas», «Máscaras del alba», "Fuente», "Repaso nocturno», "Mutra», "¿No hay salida?», "El río», «El cántaro roto» y «Piedra de sol». En este artículo, la consideración de este texto ha sido de utilidad para ejercer el tratamiento retórico, el cual será posible luego de acatar pautas críticas y sintéticas sobre su interpretación por parte de la crítica (o hermenéutica). Manuel Durán, Carlos Horacio Magis, Carmen Ruiz Barrionuevo, Victor Diaz Arciniega, Joseph Tyler, Tani Karam, Eduardo Becerra Grande y Camilo Rubén Fernández Cozman son algunos investigadores que han abordado esta obra literaria.

Primero, Manuel Durán (426) ha encontrado en los poemas de La estación violenta (1958), en especial, en "Himno entre ruinas» $\mathrm{y}$ «Piedra de sol», un sistema constante de ecos, superposición y collage de culturas, junto con un sentido cíclico y circular de la historia (eterno retorno). Esta reflexión la articula con el pensamiento estructuralista de Claude Lévi-Strauss. Segundo, Carlos Horacio Magis (340) sostiene que la máxima representación del lenguaje se observa en Semillas para un himno (1954), más que en La estación violenta (1958), pero ambos coinciden en afrontar tópicos vinculados con la idea de mostrar una visión pacífica del mundo, a pesar de sus constantes contradicciones. Tercero, Carmen Ruiz Barrionuevo (65) se refiere a este poemario como el encargado de constatar una esperanza en la palabra escrita; sin embargo, esa posición es contradictoria en la próxima producción literaria de Octavio Paz, titulada Salamandra (1962). Cuarto, Víctor Díaz Arciniega (1989) cuestiona la noción de modernidad transferida a la poesía coetánea a la producción literaria de Octavio Paz, junto con hacer mención de poemarios y poetas representativos para esa época, hasta que concluye con la incorporación de propuestas críticas hechas a la obra literaria. Quinto, Joseph Tyler (1049-1050) fundamenta la transición de los poemarios que van siendo publicados por el escritor mexicano, sin la necesidad de explicar que La estación violenta esté siendo estudiada como una ruptura entre su obra poética completa, sino que, más bien, se asumirán como cambios normales por los que atraviesa el autor. Sexto, Tani Karam (2005) aclara que, con el poemario que publica Octavio Paz en 1958 se desliga de los temas juveniles; para ello, alude al poema «Piedra de sol», que lo considera circular y lo asocia con lo amoroso y lo criminal de la historia, mediante mitos y arquetipos. Séptimo, Eduardo Becerra Grande (48) ubica detalles importantes en el poemario, pues retoma elementos que permiten hacer referencia al surrealismo. Un ejemplo de estos es el uso de la exposición del ser; además, confirma que este tipo de recursos es empleado en la obra poética de Octavio Paz, solo que es abordado desde otra perspectiva. Finalmente, Camilo Rubén Fernández Cozman (2015) demuestra en su estudio el propósito y la cosmovisión del autor, que se respalda de la diversidad de alocutarios (receptores o lectores de los poemas de La estación violenta) y la facilidad que posee para ejercer el dialogismo (conexión accesible e intercultural entre el discurso y el lector). A ese proceso, lo denomina poliacroasis (concepto desarrollado por Tomás Albaladejo), que remite a la cultura mesoamericana. Para validar su investigación, recurre al análisis figurativo y simbólico de los tropos frecuentes que se exponen en la poesía de Octavio Paz.

Luego de todas estas apreciaciones sobre La estación violenta (1958), he construido una metacrítica. Para empezar, Manuel Durán (1971) detecta las técnicas literarias que emplea Octavio Paz, sin indagar la composición teórica de las mismas. Esa omisión origina que su estudio tenga un aporte más 
ideológico (por el estudio sociológico que hace de las culturas), que metafísico (no se explica causalmente el soporte paradigmático). Seguidamente, Carlos Horacio Magis (1978), al plantear que en el poemario hay una visión pacífica y contradictoria que se corrobora en ese mundo, no abarca la totalidad, debido a que existen varios poemas que más evidencian percepciones ambiguas y caracterizadas por su conformidad o la ausencia de acción. Para Carmen Ruiz Barrionuevo (1984), el respaldo de las palabras es lo primordial. Sobre la orientación adoptada por la exégeta, concuerdo con la noción de que las palabras son un medio para consolidar un retoricismo que ralentiza el objetivo que tiene todo discurso religioso: la aceptación y la práctica de una propuesta veraz y ética. Ese proceso paulatino se erige al no haber esperanza por los cambios sociales; en consecuencia, la palabra escrita se funda como una operación de resistencia, no como un fin. Víctor Díaz Arciniega (1989), al basar su estudio únicamente en la valoración del estado de la cuestión (la hermenéutica), reduce de forma significativa los postulados que surgieron en torno al poemario de Octavio Paz; de esta manera, la lectura de su crítica es comprensible y permite la aprehensión de la ideología del escritor mexicano. Tyler (1989) y Karam (2005) se percatan del tránsito histórico de temas recurrentes en el Premio Nobel de Literatura, como el del amor, la historia y la mitificación; no obstante, este análisis es propicio si se abarca el estudio general de la obra poética del escritor mexicano. Becerra Grande (2007), al hallar rasgos del surrealismo a través de la representación del ser, no alude a la forma de exposición, compuesta por sus interacciones, su abstracción y su dinamismo. Su trabajo resulta incompleto por carecer de una orientación de análisis más estructuralista y teórica. Finalmente, Camilo Rubén Fernández Cozman (2015) recurre a conceptos propios de la retórica para interpretar los versos que propone el autor; sin embargo, su procedimiento no solo se basa en aquella estructura superficial, sino que detecta los parámetros adecuados para trascender en su análisis y demostrar ideológicamente que es posible la configuración de una poliacroasis (una direccionalidad múltiple con la inserción de elementos particulares de la cultura de Mesoamérica).

Considerando este panorama de estudios críticos, solo tendré en cuenta los poemas "¿No hay salida?» $y$ "El río", debido a que desarrollan un tema frecuente en La estación violenta (1958), como el del reforzamiento por establecer una ideología esperanzadora y progresista con respecto a los acontecimientos de la vida (en ese sentido, se obvia y se critica toda actitud que no vaya de acuerdo con ese pensamiento). Asimismo, conociendo el contenido de los poemas solo queda pendiente el dominio de la composición estilística del autor para comprender su poética. Para lograr ese propósito, en este trabajo, se aplicarán taxonómicamente los tipos de metáforas fundamentados por Lakoff y Johnson, los cuales fueron abordados por el investigador Fernández Cozman, quien retomó estos lineamientos teóricos en «El referente prehispánico y la poliacroasis en La estación violenta (1948-1957) de Octavio Paz» (2015) y «El aporte de George Lakoff» (2018a) y «Metáforas orientacionales y espacialización del sujeto en Una casa en la sombra, de Carlos López Degregori» (2018b). Al hacer referencia a estos, se articula el proceso de emparejamiento metafórico, basado en la identificación lírica de una megametáfora (concepto eje o englobante) que comprende metáforas específicas (inferidas particularmente de la megametáfora) y que, a la vez, se clasifica en metáforas orientacionales, ontológicas y estructurales, de acuerdo con el criterio que le presente el texto. A través de un estudio vinculado con estos postulados, se detectarán estos mecanismos discursivos en los poemas "¿o hay salida?» $\mathrm{y}$ «El río» de La estación violenta (1958).

En conclusión, el objetivo de este artículo es producir valores que se infieran de la ideología del autor, desde las concepciones de George Lakoff y Mark Johnson, sobre la tipología de metáforas. Para que esto sea posible, la organización asignada para los análisis de «¿No hay salida?» y «El río» se valdrá de los siguientes abordajes: la descripción teórica de la tipología de metáforas (compuesta del emparejamiento metafórico, que se conforma por las metáforas orientacionales, ontológicas y estructurales), la segmentación fundamentada de cada poema según sus temas, los tipos de metáforas, los interlocutores participantes y la cosmovisión que introduce el autor.

\section{Tipología de metáforas}

En esta ocasión, retomaré los postulados de George Lakoff y Mark Johnson (1995: 47), quienes ven necesaria la tipología de metáforas como procedimiento para producir estos tropos. Se enfocan en la inserción de ideas u objetos en recipientes o palabras, para que después sean enviados a través de un canal. Esta táctica de efectuar la emisión de información es descifrada por parte del destinatario al extraer las ideas-objetos de depósitos de significación. Por 
otro lado, es imprescindible presentar las seis razones fundamentales que el crítico Camilo Fernández Cozman (2018a) adopta para el efectivo tratamiento que se realizará con la figura retórica evaluada. De esta manera, se conocerá la importancia al haber seleccionado esta taxonomía retórica.

La primera propuesta a la que alude el investigador especializado en Lakoff y Johnson se refiere a que estas acepciones son calificadas como metafóricas mayormente. No obstante, existe una numerosa cantidad de términos pertenecientes que no corroboran con la expectativa de la significación. Por ejemplo, esto sucede cuando se menciona un significante cualquiera, como "perro». De este, se asume que su composición física (su cola, sus orejas, sus patas, sus ojos, etc.) no hace referencia inmediata a ninguna atribución connotativa preestablecida. En cambio, si se presta atención a la cualidad que posee este animal, se tendrá como resultado que la "fidelidad» es un rasgo inherente en él. En consecuencia, prevalece una correspondencia metafórica.

La segunda peculiaridad que destaca el crítico literario sobre los autores de Metáforas de la vida cotidiana es que toda metáfora oculta algo y resalta un aspecto en común. Una metáfora como «el amor es una obra de arte en colaboración» revela ese patrón. En esta, se observa cómo se privilegia la sensación amorosa positiva, que es responsable por parte de personas comprometidas. Por el contrario, se obvia la parte conflictiva o triste del enamoramiento.

El tercer rasgo que retoma Camilo Fernández Cozman en torno a la teorización de las metáforas es que se toma como base un criterio que engloba otros aspectos particulares para empezar a erigir una metáfora genérica. Con esta premisa, se infiere que predomina la naturaleza parcial como estructura metafórica. Así lo afirma Lakoff al decir que "las teorías son edificios». Para ese caso, se toman dos aspectos de los edificios: el armazón y los cimientos. Sin embargo, se obvian otros elementos para su respectiva alusión a su consolidación, como las ventanas, las escaleras y las puertas.

El cuarto referido es sobre la proximidad que hay entre elementos del lenguaje en una construcción oracional, la misma que permite que el efecto significativo posea relevancia. Esto se adquirirá con el buen uso de las metáforas, ya que estas atribuyen significado a la forma. Por ejemplo, en la expresión «Mariana vio el partido», se infiere una significación más frecuente en la vinculación del verbo «vio» con el sustantivo "el partido", porque se produce un contacto directo sin ambages en ambas palabras.
La quinta peculiaridad que Fernández Cozman (2018a) destaca sobre la base de George Lakoff (en Philosophy in the Flesh, the embodied mind and its challenge to Western Thought de 1999) es la predominancia de la razón en su cualidad de imaginativa, metafórica y comprometida emocionalmente. Por esa razón, el conocimiento estará apto para adquirir una carga más experimental de lo físico y lo sensible, como cuando el cuerpo se mueve o se percibe.

Finalmente, el crítico literario menciona como sexto criterio la clasificación de metáforas que se logra por intermedio del emparejamiento metafórico. De este, se establecen las megametáforas (orientacionales, ontológicas y estructurales) y las metáforas específicas. Para su reconocimiento en el texto, se escriben con minúscula si se trata de metáforas específicas y con mayúsculas si es la megametáfora. Por ejemplo, en los dos casos siguientes, se plantea la idea de una megametáfora que contiene a otras:

$\begin{array}{ll}\text { MEGAMETÁFORA: } & \text { «LA CASA ES UN } \\ \text { Metáforas específicas: } & \text { - Los pilares son brazos. } \\ & \text { - La puerta es la boca. } \\ \text { MEGAMETÁFORA: } & \text { «EL TIEMPO ES } \\ \text { Metáforas específicas: } & \text { - G GanÓ mucho tiempo. } \\ & \text { - Perdí algunos minutos. } \\ & \text { - Ahorré cinco segundos. }\end{array}$

En estos dos ejemplos, las megametáforas se instauran como ejes o bases que suscitan las metáforas específicas. Para concluir, luego del análisis y la comprensión de este proceso, se distinguirán los tipos de megametáforas (las orientacionales, las ontológicas y las estructurales), con el propósito de que sean reconocibles al momento de confrontar con los poemas "¿No hay salida?» y «El río», para que la designación taxonómica resulte operativa y pertinente.

\subsection{Metáforas orientacionales}

También denominadas espaciales, se encargan de organizar un sistema global de conceptos en relación con otro sistema. Según Jaime Nubiola (73-84), la mayoría de ellas se crea de la constitución física. En cambio, George Lakoff y Mark Johnson (50) sostienen que no solamente cuentan con bases físicas, sino culturales. Estas referencias temporales o espaciales pueden ser incompatibles con el tipo de metáfora que se enuncie. En consecuencia, conlleva un desvío 
de la convencionalidad interpuesta, ya que la metáfora se estructura mediante tópicos de oposición o ambigüedad. A su vez, provoca que el lector tenga múltiples bases físicas y sociales para la percepción de las metáforas. Por otro lado, algunas nociones de oposición que se priorizan son las siguientes: altobajo, adelante-atrás, arriba-abajo, derecha-izquierda, centro-periferia o profundo-superficial. Además, estas dicotomías contradictorias poseen una carga semántica designada. Por ejemplo, arriba es igual a consciente, más y bueno; mientras que abajo significa inconsciente, menos y malo.

De las metáforas orientacionales, se derivan múltiples casos de metáforas específicas. Por ejemplo, de las megametáforas «LO BUENO ES ARRIBA»y "LO MALO ES ABAJO», se configuran las siguientes metáforas específicas: "Tengo un estatus alto y él, bajo», "Le dieron de alta a tu mamá», "Posee sentimientos elevados», «Vamos cuesta abajo», «Los proyectos van hacia arriba», «Mi polo es de alta calidad y esa camisa de muy baja» $\mathrm{y}$ "Su alteza real el príncipe Guillermo de Inglaterra». Si se usaran las metáforas orientacionales de "LA VIRTUD ES ARRIBA» y "EL VICIO ES ABAJO", se destacan las siguientes metáforas específicas: «Ese señor tiene pensamientos elevados o rastreros", "Tiene bajos instintos", «Ella se dejó arrastrar por las más bajas pasiones», "Cae muy bajo o en el abismo del vicio», "La gente de esa avenida es de los bajos fondos» y "Tuvo una bajeza moral en público». Finalmente, si los postulados consistieran en "FELIZ ES ARRIBA», mientras que «TRISTE ES ABAJO", prevalecen las siguientes metáforas específicas: «Me levantó el ánimo con esa nota», "Tuve un bajón económico: estoy hundido" $y$ «Me siento bajo: he caído en una depresión».

\subsection{Metáforas ontológicas}

George Lakoff y Mark Johnson (1995: 64) las clasifican como una forma de distinguir acontecimientos, actividades, emociones, ideas, etc., de entidades y sustancias. Estas cuantifican términos más abstractos, con la intención de designarlos como objetos tangibles. Sobre ello, Jaime Nubiola (2000: 73-84) añade que se trata de la categorización de un fenómeno, de manera peculiar, por intermedio de su distinción como una entidad, una sustancia, un recipiente o una persona. A la vez, propone casos particulares, retomando la metáfora ontológica. Por ejemplo, una de ellas es "LA MENTE HUMANA ES UN RECIPIENTE», mientras que las metáforas específicas que surgen de allí son las siguientes: «Tu propuesta no me cabe en la cabeza: no me entra la lección», «Tengo algo en mente», "Tengo la mente vacía: en blanco», "Tú no me entiendes; métetelo en la cabeza», "Estoy saturado de tiempo por los estudios» $\mathrm{o}$ «Hiciste lo mismo: eres una cabeza hueca».

\subsection{Metáforas estructurales}

Surgen de la actividad o la experiencia que se estructura dentro de un concepto en términos de otro (Lakoff y Johnson 50), sin intención de hallar la cuantificación de las nociones más abstractas en rasgos más concretos. Esto sucede al enunciar «LA DISCUSIÓN ES UNA GUERRA», «EL TIEMPO ES PODER» $\mathrm{o}$ «UN DISCURSO ES UN TEJIDO». Estas megametáforas son estructurantes, porque es posible que se deriven metáforas específicas. Sobre este último ejemplo de metáfora estructural («UN DISCURSO ES UN TEJIDO»), Jaime Nubiola (73-84) articula las diversas metáforas específicas que pueden inferirse, tales como "perdí el hilo», "las ideas están mal hilvanadas o deshilvanadas», "falta un hilo argumental o conductor», "tu argumento es retorcido", "todo discurso tiene un nudo y un desenlace», etc.

Habiendo concluido con la explicación de los postulados de George Lakoff y Mark Johnson acerca de la tipología de metáforas (orientacional, ontológica y estructural), se procederá al análisis de "¿No hay salida?» y «El río» de La estación violenta (1958), de los que se ha visto importante confrontarlos con estos conceptos de emparejamiento metafórico. Antes de empezar, se aclara que para la profundización de la interpretación se incluirá la interrelación con sus respectivos interlocutores y cosmovisiones, dependiendo de cada poema.

\section{Análisis del poema «¿No hay salida?»}

Principalmente, se transcribirá el poema con la consideración de que únicamente se está empleando un fragmento (debido a su extensión), tal como se encuentra en la edición del Fondo de Cultura Económica. Igualmente, se hará una segmentación de los versos por tópicos para que se explique el porqué de la selección. Para la agrupación, se retomarán los siguientes aspectos: se enumerarán los versos del $1 .^{\circ}$ al $20 .^{\circ}$ (colocados al margen izquierdo), que se distinguirán por tópicos similares y serán encabezados 
por los títulos temáticos y la cantidad de versos que los conforman (entre paréntesis).

« No hay salida?» (Paz 37-38)

Segmento I: «Naturaleza incesante y motivadora» (versos $1 .^{\circ}$ y $\left.2 .^{\circ}\right)$

1 En Duermevela oigo correr entre bultos adormilados y ceñudos un incesante río.

2 Es la catarata negra y blanca, las voces, las risas, los gemidos del mundo confuso, despeñándose.

Segmento II: «Hacia ni un lado» (versos $3 .^{\circ}$ y $4 .^{\circ}$ )

$3 \mathrm{Y} \mathrm{mi}$ pensamiento que galopa y galopa y no avanza, también cae y se levanta

4 y vuelve a despeñarse en las aguas estancadas del lenguaje.

Segmento III: «Múltiples posibilidades

provechosas» (versos del 5. ${ }^{\circ}$ al $8 .^{\circ}$ )

5 ¡Palabras para sellar al mundo con un sello indeleble o para abrirlo de par en par,

6 sílabas arrancadas al árbol del idioma, hachas contra la muerte, proas donde se rompe la gran ola del vacío,

7 heridas, surtidores, conos esbeltos que levanta el insomnio!

8 Hace un segundo habría sido fácil coger una palabra y repetirla una y otra vez,

Segmento IV: «Otra vez el pesimismo» (versos del 9. ${ }^{\circ}$ al $\left.11 .^{\circ}\right)$

9 cualquiera de esas frases que decimos a solas en un cuarto sin espejos

10 para probarnos que no es cierto,

11 que aún estamos vivos,

Segmento V: «De vuelta a la vida, el eterno presente» (versos del $12 .^{\circ}$ al $20 .^{\circ}$ )

12 pero ahora con manos que no pesan la noche aquieta la furiosa marea

13 y una a una desertan las imágenes, una a una las palabras se cubren el rostro.

14 Pasó ya el tiempo de esperar la llegada del tiempo, el tiempo de ayer, hoy y mañana,

15 ayer es hoy, mañana es hoy, hoy todo es hoy, salió de pronto de sí mismo y me mira,

16 no viene del pasado, no va a ninguna parte, hoy está aquí, no es la muerte
17 -nadie se muere de la muerte, todos morimos de la vida-, no es la vida

18 - fruto instantáneo, vertiginosa y lúcida embriaguez, el vacío sabor de la muerte da más vida a la vida-,

19 hoy no es muerte ni vida,

20 no tiene cuerpo, ni nombre, ni rostro, hoy está aquí, echado a mis pies, mirándome.

He dividido el poema "¿No hay salida?» en cinco segmentos, los cuales tienen un título que engloba el tema que trata los versos agrupados. Esta recopilación la explicaré a continuación. El segmento I: «Naturaleza incesante y motivadora» (versos $1 .^{\circ}$ y $\left.2 .^{\circ}\right)$ se denomina de esta forma por la pretensión de mostrar frecuentemente un elemento especial de la naturaleza, el río, que trae consigo una simbología progresista. Además, se ve su confrontación con entidades que están distanciadas de este aspecto. Por lo tanto, la significación se expone en ese contraste semántico. El segmento II: «Hacia ni un lado» (versos $3 .^{\circ} \mathrm{y} 4 .^{\circ}$ ) se ha asignado de esa manera, porque se reconoce el estadio del ser manifestado en la nada; es decir, hay un desinterés y una inacción de la vida. Frases como "no avanza» o "aguas estancadas» demuestran esa imposibilidad humana de desarrollarse. Ahora, si se toma como referencia la primera parte, se adopta la idea de que concurre un rechazo a la oportunidad de redirigir la vida, una totalmente esperanzadora y desligada de problemas. El segmento III: «Múltiples posibilidades provechosas» (versos del $5 .^{\circ}$ al $8 .^{\circ}$ ) es una propuesta o una serie de alternativas en la que se observa qué tan provechosa es la vida. Ante ello, se pone como referencia el desenvolvimiento que prevalece en situaciones estancadas o dolorosas, pero la finalidad que se tiene en exteriorizarlas es para develar el lado óptimo y triunfador que posee el simple hecho de asumir la existencia con ansias, debido a que suscitará todo conflicto. En el segmento IV: «Otra vez el pesimismo» (versos del 9. al $\left.11 .^{\circ}\right)$, se ve que el sujeto al interiorizarse resulta agredido, impuro, insano, por lo que rápidamente libera su ausencia de deseo por seguir viviendo o, mejor dicho, anula toda sensibilidad para retomar la parte altiva y festiva de ese preciso instante en el que se le proporciona la vida. El último segmento: «De vuelta a la vida, el eterno presente» (versos del $12 .^{\circ}$ al $20 .^{\circ}$ ) es un apartado dedicado a la idea de sincretizar toda ideología plasmada a lo largo del poema, porque resume y discrimina sensibilidades ya semantizadas con anterioridad, con el objetivo de abstraer todas las significaciones (tiempos, elementos de la naturaleza 
y vivencias) a la actualidad, la vida, la esperanza y el progreso.

\subsection{Tipología de metáforas en "NNo hay salida?"}

En este poema, la tipología de metáforas se halla en dos oportunidades, que se construyen convencionalmente por las metáforas específicas.

El primer caso se identifica en la megametáfora «RESISTENCIA A OLVIDAR EL DOLOR POR CUBRIRLO DEL BIEN». De esta, se asocian las siguientes metáforas específicas: «Y mi pensamiento que galopa y galopa y no avanza, también cae y se levanta» (verso $3 .^{\circ}$ ) y de los versos del $9 .^{\circ}$ al $13 .^{\circ}$ :

cualquiera de esas frases que decimos a solas en un cuarto sin espejos

para probarnos que no es cierto,

que aún estamos vivos,

pero ahora con manos que no pesan la noche aquieta la furiosa marea

y una a una desertan las imágenes, una a una las palabras se cubren el rostro.

Ante ello, se reconoce la remembranza del pensamiento o el recuerdo, que se simboliza o se expresa por «palabras» que retornan, junto con escenarios y hechos vividos (atrapados en el tiempo). Esto censura al yo poético, aunque le hace vivir una felicidad particular, que se torna irreal por no confrontar con el presente.

La segunda megametáfora que genera emparejamientos metafóricos es cuando se niegan atribuciones correspondientes a significantes importantes, como la vida y la muerte. Por lo tanto, ante la resistencia vista en el emparejamiento anterior, la que se conforma en esta ocasión es la megametáfora "LA VIDA Y LA MUERTE PIERDEN SUS SIGNIFICADOS». Al respecto, las metáforas específicas se localizan en los versos del $14 .^{\circ}$ al $19 .^{\circ}$ :

Pasó ya el tiempo de esperar la llegada del tiempo, el tiempo de ayer, hoy y mañana,

ayer es hoy, mañana es hoy, hoy todo es hoy, salió de pronto de

sí mismo y me mira,

no viene del pasado, no va a ninguna parte, hoy está aquí, no es

la muerte

—nadie se muere de la muerte, todos morimos de la vida—, no es la vida

— fruto instantáneo, vertiginosa y lúcida embriaguez, el vacío

sabor de la muerte da más vida a la vida-,

hoy no es muerte ni vida.

En la selección de estos versos, predomina la idea de renacer o refutar los significantes de vida y muerte, que tienden a desvirtuarse porque el locutor les está negando no solo su valor, sino la preponderancia de respaldarse de una sola postura, de manera disyuntiva. Ahora, al desconocer y estar en duda de lo que significan estas palabras en "¿No hay salida?», conlleva que se cuestionen los resultados que genera cada una de ellas, que suscita cuando se finaliza con «hoy no es muerte ni vida» (verso $19 .^{\circ}$ ).

En estos dos ejemplos, se instauran megametáforas que conllevarán sus respectivas metáforas específicas. De igual modo, se infiere que estas se presentan desde sus tres variantes: las metáforas orientacionales, ontológicas y estructurales.

\subsubsection{Metáforas orientacionales en «¿No hay salida?»}

En este poema, se encuentran casos ambivalentes. La oposición predominante es la de adelante-atrás, porque la acción se centra en equiparar estos movimientos. Por ejemplo, si el personaje tiende a retroceder, posee ya una carga preferentemente negativa, mientras que si avanza será lo inverso. Por ello, estableceré dos megametáforas, contrarias entre sí. Estas son "QUIEN AVANZA, PROGRESA» contra «QUIEN SE QUEDA ATRÁS, SE DESTRUYE». Estas acepciones son atribuidas convencionalmente, ya que la dirección asignada indica una posición más perteneciente al grado de capacidad pragmático sobre el mundo, como lo revela el 3. ${ }^{\text {er }}$ verso, del cual "galopa» y «levanta» simbolizan el progreso. Entretanto, «no avanza» $\mathrm{y}$ "cae» representan el retroceso. Ahora, con la intención de exteriorizar versos hallados con las metáforas específicas de la megametáfora orientacional ya descrita, haré la siguiente clasificación.

Primero, se infiere la megametáfora «QUIEN AVANZA, PROGRESA», que se esclarece en las metáforas específicas «Mi pensamiento que galopa y galopa [...] y se levanta» (verso $3 .^{\circ}$ ), «[...] para abrirlo de par en par» (verso $5 .^{\circ}$ ), «[... qu que levanta el insomnio» (verso $\left.7 .^{\circ}\right)$, «[...] habría sido fácil coger una palabra y repetirla una y otra vez» (verso $8 .^{\circ}$ ) y "[...] salió de pronto de sí mismo y me mira» (verso 15..$^{\circ}$. Las ideas de galopar, levantar, abrir, coger, 
repetir y salir implican la noción de movimiento o avance, ya que el ser tiende a quebrantar lo estático, vive, entra en confrontación con los objetos y el propio mundo. Por ello, enfocan la idea de progresar por el resultado que se obtiene. Luego de ejecutar una determinada acción, se consigue un fin objetivo y gratificante.

Segundo, se construye la megametáfora "QUIEN SE QUEDA ATRÁS, SE DESTRUYE», que corresponde con «En Duermevela [...] entre bultos adormilados [...]» (verso $\left.1 .^{\circ}\right)$, «Y mi pensamiento [...] no avanza, también cae $[\ldots]$ » (verso $\left.3 .^{\circ}\right)$, «[...] aguas estancadas $[\ldots]$ » $\left(\right.$ verso $\left.4 .^{\circ}\right)$, «Pasó ya el tiempo de esperar la llegada del tiempo [...]» (verso 14. $\left.{ }^{\circ}\right)$, «no viene del pasado, no va a ninguna parte [...]» (verso 16), «-nadie se muere de la muerte, todos morimos de la vida [...]» (verso $17 .^{\circ}$ ) y «no tiene cuerpo, ni nombre, ni rostro, hoy está aquí, echado a mis pies, mirándome» (verso $20 .^{\circ}$ ). En los casos mostrados, las ideas de dormir, no avanzar, caer, estancar, pasar, no ir o morir revelan una carga semántica de retroceso o inacción, que conduce a la improductividad, por lo tanto, a la muerte próxima o la destrucción de los mismos.

\subsubsection{Metáforas ontológicas en "¿No hay salida?»}

En este poema, se aprecia un caso en el que se desarrolla la metáfora ontológica al inferirse la megametáfora "LA MEMORIA DOLOROSA DESTRUYE» de los versos $7 .^{\circ}$ y $17 .^{\circ}$ : «heridas, surtidores, conos esbeltos que levanta el insomnio" y "-nadie se muere de la muerte, todos morimos de la vida-, no es la vida» (metáforas específicas). De estos, se extrae la idea de que el recuerdo doloroso aún permanece en el tiempo y que eso provoca una inacción en el sujeto, una limitación o una angustia de sentir la muerte próximamente. Igual sucede con la megametáfora "LO INCONTROLABLE ANGUSTIA», de la que se ve que no es la sensación de muerte, ni el recuerdo, ni la inacción, sino el hecho de no saber qué hacer por esa angustia generada por los problemas, las limitaciones o los malos recuerdos que se han infundido en el ser, lo cual provoca una serie de descripciones que no tiene sentido ni fin alguno, tal como se representa a continuación:

Pasó ya el tiempo de esperar la llegada del tiempo, el tiempo de ayer, hoy y mańana,

ayer es hoy, mañana es hoy, hoy todo es hoy, salió de pronto de sí mismo y me mira, no viene del pasado, no va a ninguna parte, hoy está aquí, no es la muerte (versos del $14 .^{\circ}$ al $16 .^{\circ}$ ).

\subsubsection{Metáforas estructurales en «¿No hay salida?»}

En este poema, es relevante mediante la megametáfora que se forma del siguiente enunciado: «LO DESCONOCIDO ES UNA ESPERANZA». La misma que conforma metáforas específicas en los versos del $18 .^{\circ}$ al $20 .^{\circ}$ : «-fruto instantáneo, vertiginosa y lúcida embriaguez, el vacío sabor de la muerte da más vida a la vida-, / hoy no es muerte ni vida, / no tiene cuerpo, ni nombre, ni rostro, hoy está aquí, echado a mis pies, mirándome». Como se observa, ante la sensación de soledad y angustia, se encuentra una reflexión que parte de la vida y la muerte, sin que exista la posibilidad de salir de ambas alternativas, tal como se muestra en el verso $19 .^{\circ}$ : "hoy no es muerte ni vida». A pesar de eso, existe una necesidad de seguir refutando, por el hecho de que se intenta llegar a una esperanza a través de este tipo de discurso dialéctico.

\subsection{Interlocutores en "¿No hay salida?»}

En el libro Rodolfo Hinostroza y la poesía de los años sesenta (2009), Camilo Fernández Cozman propuso la conceptualización de los interlocutores, factible para la comprensión del procedimiento interno y externo de la enunciación. Los agentes mediadores son el autor real, el autor implicado, el locutor, el alocutario, el lector implicado y el lector real, que se articulan interactivamente, tal como se explicará a partir del siguiente gráfico:

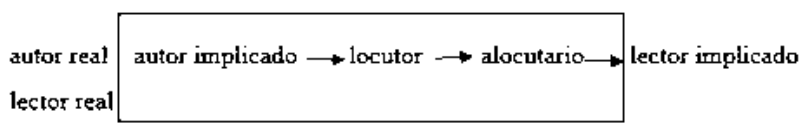

1. El autor real. Su intervención es notoria en la vida cotidiana, pues está presente y existe (Ricoeur 886). Posee una ideología característica y sus acciones son narrables, es decir, es posible la construcción de una biografía del mismo. Según Umberto Eco (63), se trata de quien inserta libremente palabras en un discurso. Del mismo modo, asume una conducta inestable (Auerbach 504): puede ser eufórico, imponente o radical, dependiendo de su intencionalidad. Se encarga de incluir al autor implicado (su participación textual). 
2. El autor implicado. Es toda aquella entidad pensante que cuenta con conocimientos afines a los propósitos del texto, por lo que es notorio identificarle un estilo distinguido (Ricoeur 886). Tiene a su disposición la configuración del locutor que se corroborará en los poemas. A través de ese establecimiento, conllevará la comunicación con el lector implicado.

3. El locutor. Adelso Yáñez (2000) lo define como la instancia que se expresa mediante el lenguaje, caracterizado por su interpretación denotativa y connotativa. Este se manifiesta de dos maneras. La primera es por el locutor personaje, evidente por aludir al yo poético y confrontar con la 1. a persona del singular (se emplea el «yo», junto con los deícticos «mi» $\mathrm{y}$ «mío»). La segunda es por medio del locutor no personaje, el cual requiere el dominio de la 3. ${ }^{a}$ persona del singular o el plural, por lo que su discurso es menos subjetivo y más pretencioso.

4. El alocutario. Es el público o el receptor del mensaje, el mismo que puede estar representado (se reconoce un «tú»), como también oculto (se desconoce al destinatario). Por otro lado, entre el locutor y el alocutario, existen tres modalidades de inmersión. Una de ellas se visibiliza al hallarse el locutor personaje con el alocutario no representado (se manifiesta el monólogo). Otra forma es cuando es notoria la participación del locutor personaje con el alocutario representado (se enfoca en la pragmática). Finalmente, se expone la relación del locutor no personaje con el alocutario no representado (se articula el monólogo externo, por lo que se tiende a la descripción).

5. El lector implicado. Wolfgang Iser (Martínez Fernández, 2001) lo desarrolla para hacer referencia a aquella entidad a la que el autor implicado cree que está dirigiéndose. Consiste en una proyección utópica e imaginaria de la recepción del texto, como el hecho de pensar que un tipo de lector contará con la capacidad para discernir cabalmente el contenido y la estructura superficial de una novela (Beristáin 91).

6. El lector real. Es la persona real que confronta el texto y no se encuentra inmerso en la configuración del mismo. Está apto para emitir un juicio (Beristáin 127) o direccionar un discurso (Eco 63). Además de ello, busca en el proceso de la lectura el goce ante la conformación de esa estética escrita (Barthes, 1998, Auerbach 377).

Habiendo concluido con la explicación teórica de los interlocutores, haré la primera aplicación conceptual en el poema "No hay salida", en el que prevalecen dos tipos de locutores y alocutarios.
En torno a los locutores, en el primer caso, hay referencia a un locutor no personaje, ya que implica un carácter más objetivo, externo y focalizante al no identificarse el «yo», sino a la $3 .{ }^{a}$ persona del singular («él»): «Es la catarata negra y blanca, las voces, las risas, los gemidos del mundo confuso, despeñándose» (2..$^{\circ}$ verso). De la misma manera, se muestran en los versos $8 .^{\circ}, 14 .^{\circ}, 16 .^{\circ}, 18 .^{\circ}$ y $19 .^{\circ}$. No obstante, se representa este tipo de locutor no personaje en la 3. ${ }^{a}$ persona del plural: «iPalabras para sellar al mundo con un sello indeleble o para abrirlo de par en par» (5. verso), como también ocurre con los versos $6 .^{\circ}$, $7 .^{\circ}, 8 .^{\circ}, 12 .^{\circ}$ y $13 .^{\circ}$. En el segundo caso, se trata de un locutor personaje que está escrito en la $1 .^{a}$ persona del singular. Esto lo revelan los deícticos incluidos en los verbos, como "oigo" (verso $1 .^{\circ}$ ), junto con la aparición del «yo» (versos $3 .^{\circ}, 4 .^{\circ}$ y $\left.15^{\circ}\right)$. En ese sentido, se reafirma la existencia de un yo poético.

En relación con el alocutario, se encuentran los dos tipos: el alocutario representado y el que no lo está. El primero, quien es destinatario del locutor, se evidencia con la marca deíctica del «nosotros»: «todos morimos» (verso 17. ${ }^{\circ}$ ), «decimos» (verso 9. ${ }^{\circ}$ ), "probarnos» (verso $10 .^{\circ}$ ) y «estamos» (verso $\left.11 .^{\circ}\right)$. En el segundo caso, el alocutario no es explícito. Tampoco existen deícticos ni representaciones de personas o destinatarios a quienes se les envía el mensaje persuasivo. Esto se expone a lo largo de «¿No hay salida?», a excepción de los versos anteriormente mencionados. Por ejemplo, en el verso $14{ }^{\circ}$, no hay deícticos de la 2. ${ }^{a}$ persona: «Pasó ya el tiempo de esperar la llegada del tiempo, el tiempo de ayer, hoy y mańana». En esta ocasión, se exhibe a la $3 .{ }^{a}$ persona del singular.

\subsection{Cosmovisión en "¿No hay salida?"}

Considerando a Gérard Genette (116), se comprende la noción de cosmovisión como una construcción ideológica y estilística autónoma, la cual caracteriza a cada poeta. Esta intenta revelar el vínculo que prevalece entre el hombre con su sociedad. Esto le permitirá polemizar sobre acontecimientos que se hallan en conocimiento de la mayoría de ciudadanos. Esa proximidad sobre la perspectiva que se configura desde el lenguaje se logra al referirse a un tópico específico de manera accesible y de fácil entendimiento. Su propósito es alcanzar la reflexión en el lector o el destinatario.

Para el caso de «¿No hay salida?», se muestra una vez más el tránsito del ser (constante en varios poemas de La estación violenta). Al respecto, es primordial el 
planteamiento desde la inacción, junto con la idea de dramatizar elementos o situaciones en las que la vida le hace notar la oportunidad que le brinda para modificar su estado anímico. Finalmente, concluye ese recorrido humano en la adopción de un estado altivo, el cual lo ayuda y lo reorienta. En general, la cosmovisión de Octavio Paz es anular toda sensación que fuera improductiva: no comparte la concepción de confrontar con alguien que piensa más en la muerte que vivir objetiva y productivamente el tiempo y el espacio en donde está. Como punto de referencia, se hallan la vida y todo lo que la instaura (apreciables en el pasado, el presente y el futuro), ya que a partir de allí se hace un balance de cómo se generan las sensibilidades en las personas.

\section{Análisis del poema «El río»}

$\mathrm{Al}$ igual que como se procedió en el poema anterior, se introducirá un fragmento de este poema, tal como se muestra en la edición del Fondo de Cultura Económica, con la incorporación personal de segmentaciones enumeradas al lado izquierdo de los versos $1 .^{\circ}$ al $19 .^{\circ}$, según la cantidad de tópicos encontrados. Las agrupaciones tendrán un título convencional en la parte superior, que los represente y que luego serán explicados. Posterior a este análisis, se tratará el tipo de metáforas que proponen Lakoff y Johnson, junto con la identificación que se realizará de sus interlocutores y su cosmovisión.

«El río» (Paz 42-44)

Segmento I: «La memoria del reclamo colectivo» (versos del $1 .^{\circ}$ al $8 .^{\circ}$ )

1 LA CIUDAD desvelada circula por mi sangre como una abeja.

2 Y el avión que traza un gemido en forma de $S$ larga, los tranvías que se derrumban en esquinas remotas,

3 ese árbol cargado de injurias que alguien sacude a medianoche en la plaza,

4 los ruidos que ascienden y estallan y los que se deslizan y cuchichean en la oreja un secreto que repta

5 abren lo obscuro, precipicios de aes y oes, túneles de vocales taciturnas,

6 galerías que recorro con los ojos vendados, el alfabeto somnoliento cae en el hoyo como un río de tinta,
7 y la ciudad va y viene y su cuerpo de piedra se hace añicos al llegar a mi sien,

8 toda la noche, uno a uno, estatua a estatua, fuente a fuente, piedra a piedra, toda la noche

Segmento II: «Víctima de la sociedad» (versos 9. y $\left.10 .^{\circ}\right)$

9 sus pedazos se buscan en mi frente, toda la noche la ciudad habla dormida por mi boca

$10 \mathrm{y}$ es un discurso incomprensible y jadeante, un tartamudeo de aguas y piedra batallando, su historia.

Segmento III: «El ser y la nada» (versos del $11 .^{\circ}$ al $\left.19 .^{\circ}\right)$

11 Detenerse un instante, detener a mi sangre que va y viene, va y viene y no dice nada,

12 sentado sobre mí mismo como el yoguín a la sombra de la higuera, como Buda a la orilla del río, detener al instante,

13 un solo instante, sentado a la orilla del tiempo, borrar mi imagen del río que habla dormido y no dice nada y me lleva consigo,

14 sentado a la orilla detener al río, abrir el instante, penetrar por sus salas atónitas hasta su centro de agua,

15 beber en la fuente inagotable, ser la cascada de sílabas azules que cae de los labios de piedra,

16 sentado a la orilla de la noche como Buda a la orilla de sí mismo ser el parpadeo del instante,

17 el incendio y la destrucción y el nacimiento del instante y la respiración de la noche fluyendo enorme a la orilla del tiempo,

18 decir lo que dice el río, larga palabra semejante a labios, larga palabra que no acaba nunca,

19 decir lo que dice el tiempo en duras frases de piedra, en vastos ademanes de mar cubriendo mundos.

Para el poema «El río», he hecho una división por tópicos que se constituyen en tres partes que abordan versos en común afluencia. Estos serán desarrollados a continuación. En el segmento I: «La memoria del reclamo colectivo» (versos del $1 .^{\circ}$ al $8 .^{\circ}$ ), se ve cómo el yo poético es testigo y cómplice de lo que vive la colectividad con la que ha pasado un momento de su vida. La memoria se muestra patente allí, ya que prevalece una inquietud que comúnmente contrarresta su tranquilidad; es más, el enunciador se siente comprometido por un cambio social (progreso). El 
segmento II: «Víctima de la sociedad» (versos $9 .^{\circ} \mathrm{y}$ $\left.10 .^{\circ}\right)$ enuncia las posibilidades y las limitaciones del yo poético, que son solamente una exteriorización producida por esa colectividad que reclama y se queja de las insatisfacciones y las limitaciones existentes en esa realidad. En el segmento III: «El ser y la nada» (versos del $11 .^{\circ}$ al $19 .^{\circ}$ ), se exhibe la idea de que el hombre ejercerá acciones, mas no habrá cambios significativos; es decir, todo lo que haga no tendrá sentido, pues se encuentra condenado a volver a repetir lo que realizaron sus ancestros y las personas coetáneas a él. Por eso, recurre a imágenes como las del Buda, el estar dormido y la nada.

\subsection{Tipología de metáforas en «El río»}

En los primeros diecinueve versos de este poema, se hallan dos tipos de megametáforas como emparejamientos metafóricos, los cuales han sido construidos convencionalmente, a partir de las metáforas específicas que se infieren.

La primera megametáfora constituida es «EL SER ES UNA REPRESENTACIÓN DE SU ENTORNO», la cual es factible configurar a partir de las siguientes metáforas específicas: «La ciudad desvelada circula por mi sangre como una abeja» (verso $1 .^{\circ}$ ) y «sus pedazos se buscan en mi frente, toda la noche la ciudad habla dormida por mi boca» (verso $9 .^{\circ}$ ). De ello, se observa cómo el yo poético va consolidando su identidad a partir de recuerdos y vivencias diferenciados por la sociedad con la que ha transcurrido a lo largo de su vida. Esta revelación es patente al momento de que el locutor es quien se expresa por medio de palabras, que tienen en común la manera particular de exteriorizarse con los demás ciudadanos que componen su colectividad. Además de representarse similar (a través del lenguaje), se intuye que la interioridad ha sido adaptada de tal forma que coloca a la humanidad en un plano de carencia progresista (los constantes reclamos emitidos por su colectividad establecen también un modo de ser del mismo).

La segunda megametáfora que se erige es «LAS ACCIONES SON EN VANO», la cual se conforma de las metáforas específicas, que se evidencian desde los versos $11 .^{\circ}$ hasta el $19 .^{\circ}$; por ejemplo, son notorias en el verso $11 .^{\circ}$ desde el siguiente modo: "va y viene, va y viene y no dice nada». En el $12 .^{\circ}$, se detectan «sentado", "como Buda», "detener al instante». Del $13 .^{\circ}$, se halla la metáfora específica "del río que habla dormido y no dice nada y me lleva consigo"; del $14 .^{\circ}$, «abrir el instante». Del verso $15 .^{\circ}$, se encuentra la metáfora específica «beber en la fuente inagotable»; del $16 .^{\circ}$, «sentado en la orilla»; del $17 .^{\circ}$, «el incendio y la destrucción y el nacimiento del instante»; del $18 .^{\circ}$, «larga palabra que no acaba nunca»; y del 19.': «decir lo que dice el tiempo". Si bien he transcrito las metáforas específicas, que no es la totalidad del verso en sí, en cada caso, pues se asume la idea de que la acción de la humanidad tiende a no conseguir un cambio por el reclamo de la sociedad. Ideas, estéticas, filosofías, arte, política, religiones, entre otras formas de representar, no han logrado lo que la gente protesta: una alteración en el orden de las cosas que los conduzca a la tranquilidad, la felicidad y el progreso.

En estos dos ejemplos expuestos, se instauran megametáforas con sus respectivas metáforas específicas. Esta identificación posibilita que se aborden sus tres modalidades: las metáforas orientacionales, ontológicas y estructurales.

\subsubsection{Metáforas orientacionales en «El río»}

En este poema, se encuentra este tipo de metáfora con notoriedad. A continuación, se fundamenta que lo patentizado parte de la temática dual de las orientaciones de profundidad-superficialidad, puesto que la exteriorización se articula. El caso consiste en formular las megametáforas de oposición entre las frases «LO REPRESENTADO ES LO REAL, QUE ESTÁ EN DETERIORO» con «LO NO REPRESENTADO ES ILUSORIO Y BELLO». El primer enunciado se registra en los versos del $1 .^{\circ}$ al $10 .^{\circ}$, sobre todo en el verso $7 .^{\circ}$, en el que el yo poético expresa su opinión sobre el conocimiento de la realidad: "y la ciudad va $\mathrm{y}$ viene y su cuerpo de piedra se hace añicos al llegar a mi sien»; es decir, el hecho de tener en cuenta que la sociedad está desconfigurada implica conocer sus estructuras, tanto internas como externas. Por eso, la decepción del locutor pretende respaldarse en una postura crítica de reclamo social. Para el segundo caso, las metáforas específicas están compuestas por los diecinueve versos de este poema, que tienden a hacer una descripción muy pesimista de la realidad. En consecuencia, no existe un contramodelo que se oponga al deterioro de un lugar o una sociedad.

\subsubsection{Metáforas ontológicas en «El río»}

En el poema, se ve de qué modo aquellas particularidades de la naturaleza asumen una significación 
que permite clasificarlas como vinculadas o pertenecientes a caracterizaciones humanas. Por esa razón, señalo una megametáfora evidente, como la de señalar que «EL SER SE CONFORMA DE TODA LA NATURALEZA QUE LO RODEA». Por otro lado, en el verso $3 .^{\circ}$ : «ese árbol cargado de injurias que alguien sacude a medianoche en la plaza", se interpreta que ese elemento representa a la gente adulta que habita en ese espacio geográfico y que conoce muy bien la historia de su colectividad, a la cual pertenece. De ahí, se extrae que cuando se refieren a "sacudir» se alude obviamente a que alguien está reclamándoles a los que han vivido esa etapa de quejas e injusticias para que cuenten la historia de su lugar de origen, con la intención de que se provoque una revuelta de manera lógica o simplemente para ser precavido en un futuro. Todo esto se enfoca como una vía lógica para emprender la constitución de una nación. En el verso $10 .^{\circ}$, sucede lo mismo: «y es un discurso incomprensible y jadeante, un tartamudeo de aguas y piedra batallando, su historia», en el cual los elementos de la naturaleza integran el pasado que aún pervive mediante el reclamo y la disconformidad.

\subsubsection{Metáforas estructurales en «El río»}

En este poema, se aprecian dos tipos de metáforas estructurales. El primero se genera del enunciado «LA INACCIÓN ES LA COMPRENSIÓN», como se evidencia en el verso $12{ }^{\circ}$ con su respectiva metáfora específica: «Sentado sobre sí mismo como el yoguín a la sombra de la higuera, como Buda a la orilla del río, detener el instante». En ese caso, prevalece la conformidad con el yo poético, ya que este acepta la derrota y sabe que no puede hacer nada para alterar el orden. Esta decisión es adoptada por el hecho de que a él le precede ya una generación que exige en ese presente. La segunda megametáfora estructural se conforma a partir de la oposición de la primera: «EL RECLAMO ES LA INCONFORMIDAD DE LA VIDA». Por ejemplo, el verso 18..$^{\circ}$ "decir lo que dice el río, larga palabra semejante a labios, larga palabra que no acaba nunca» muestra un tipo de discurso que permanece en la ideología de "El río», como el hecho de que existe un reclamo constante, fundado con anterioridad, que tiende a limitar el acceso a la felicidad de la vida de aquel presente, el cual está totalmente anulado por la idea de que hay una insatisfacción por los cambios que no llegarán a una sociedad.

\subsection{Interlocutores en "El río»}

Hay dos tipos de locutores en este poema que se exhiben de manera alterna y solo uno de alocutario.

Con respecto a los locutores, en el primer caso, se trata de un locutor personaje que está escrito en 1. ${ }^{a}$ persona del singular. Esto lo revelan los deícticos incluidos en las acciones, como en los versos $1 .^{\circ}, 6^{\circ}$, $7 .^{\circ}, 9 .^{\circ}, 11 .^{\circ}, 12 .^{\circ}$ y $13 .^{\circ}$. Véase, por ejemplo, el verso $9 .^{\circ}:$ «mi frente» y «mi boca», motivo por el cual se reafirma la existencia de un yo poético. Este tipo de locutor se muestra de forma intercalada en «El río». En el segundo caso, hay referencia a un locutor no personaje, ya que implica un carácter más objetivo, externo y focalizante al no identificarse el «yo», sino la $3 .^{a}$ persona del singular («él»), respectivamente: "Toda la noche, uno a uno, estatua a estatua, fuente a fuente, piedra a piedra, toda la noche» (verso $8 .^{\circ}$ ). Se evidencia del mismo modo que en el caso anterior en los versos $2 .^{\circ}, 3 .^{\circ}, 10 .^{\circ}$ y del $14 .^{\circ}$ al $19 .^{\circ}$. No obstante, también, hay una representación de este locutor no personaje en $3 .^{a}$ persona, pero del plural («ellos»), como se observa en los versos $4 .^{\circ}$ y $5 .^{\circ}:$ "Los ruidos que ascienden y estallan y los que se deslizan y cuchichean en la oreja un secreto que repta, / abren lo oscuro, precipicios de aes y oes, túneles de vocales taciturnas».

El alocutario en los dos ejemplos no está exteriorizado, ya que no existen deícticos ni exhibiciones de personas o destinatarios a quienes se les envíe el mensaje persuasivo.

\subsection{Cosmovisión en «El río»}

El fragmento elegido de este poema muestra una percepción del mundo muy limitada al mencionar que ciertas personas están condenadas a no aportar, debido al contexto y la sociedad en los que viven. Por ese lado, el ser es aquella instancia que se representa y se condena por su discurso o sus acciones. No existe una alternativa, esa esperanza de poder solucionar todo, ya no hay un modelo para imitar. Ahora, lo predominante es una variación de análisis antropológico: la humanidad se rige por el medio en donde se ha criado (allí las personas en conjunto se desenvuelven y conviven).

\section{Conclusiones}

Los análisis elaborados por la crítica literaria (Manuel Durán, Carlos Horacio Magis, Carmen Ruiz 
Barrionuevo, Víctor Díaz Arciniega, Joseph Tyler, Tani Karam, Eduardo Becerra Grande y Camilo Fernández Cozman) a La estación violenta coinciden en un tema frecuente: la posición optimista y de progreso que debe asumir el hombre frente al mundo, pese a que existan tribulaciones. Sobre esa base, se interpretaron las metáforas halladas en los poemas, con el propósito de entender la perspectiva del poeta.

La configuración conceptual en torno a los tipos de metáforas planteados por Lakoff y Johnson, estudiados por el investigador Fernández Cozman, facilitó el hallazgo del procedimiento que generaba las expresiones poéticas de «¿No hay salida?» $\mathrm{y}$ «El río». Además, la comprensión del discurso dependió de la eficacia de la taxonomía retórica para inferir instantes en los que las filiaciones entre significantes y significados fueron distinguidas de un eje inamovible, extraído de la obra literaria. En ese sentido, un concepto como el emparejamiento metafórico originó el reconocimiento pertinente de sus componentes: la megametáfora y las metáforas específicas.

Con el respaldo de las metáforas orientacionales, ontológicas y estructurales, analizadas por George Lakoff y Mark Johnson, el postulado del escritor mexicano es más notorio por la transferencia directa que posee su enunciado lírico en La estación violenta, basado en el interés por incluir todo pensamiento que busque la superación personal y humanitaria, fundada en valores y progreso para la sociedad. A su vez, se critica toda postura que opte la inacción, el rechazo o la actitud desigual hacia lo que se promulga como correcto y esperanzador.

En torno a los agentes que intervienen como interlocutores de la comunicación (conceptualizados por Fernández Cozman, Ricoeur, Eco, Auerbach, Yáñez, Iser, Beristáin, Doležel y Barthes), se logró el rol fundamental de comprender la conformación de la misma para facilitar la orientación interpretativa del discurso retórico de Octavio Paz. En «¿No hay salida?» y "El río», se produce un abordaje exclusivo e interactivo para suscitar el interés de quienes integran mayormente ese circuito de participación enunciativa (locutores y alocutarios expuestos de diversas maneras).

La cosmovisión, entendida por Gérard Genette (1993), consistió en la postura que adopta el autor con respecto a un problema que acontece en la sociedad. De La estación violenta, se identifica el juicio que se emite hacia aquellas personas que se hallan en un estado inactivo. Esa actitud es criticable porque el lector implicado instaura la posibilidad de distinguir cuáles son los síntomas de retraso y barbarie en función de esa indiferencia al anhelo por la vida (el progreso de la humanidad).

Finalmente, para esta forma de analizar la retórica patentizada por el autor, fue indispensable la configuración de una taxonomía autónoma del tipo de metáforas, los interlocutores y la cosmovisión. Su exposición consiguió el fin esperado de su inclusión: el aprendizaje y la retención de la poética y la cosmovisión de Octavio Paz. Con lo instruido, no solo se retoma la ideología cuestionada (el interés por el progreso en la humanidad), sino que se establece un método propio para confrontar con las figuras retóricas que se localizan en los discursos complejos, como el de la poesía.

\section{Bibliografía}

Auerbach, Erich. Mimesis. La representación de la realidad en la literatura occidental. México: Fondo de Cultura Económica, 1996.

BARTHEs, Roland. El placer del texto y Lección inaugural. De la cátedra de semiología literaria del collage de france. México: Siglo Veintiuno Editores, 1998.

Becerra Grande, Eduardo. «Mariposa de obsidiana», de Octavio Paz: el surrealismo y la voz del mito. América sin Nombre, 9-10, (2007): 43-48.

Beristáin, Helena. Análisis estructural del relato literario. México, D. F.: Universidad Nacional Autónoma de México, 1997.

Delgado Del Aguila, Jesús Miguel. «El discurso retórico en Trilce (1922), perlocutivo para el afianzamiento del núcleo familiar». Revista Iberoamericana de Argumentación, 17, (2018): 23-60.

Diaz Arciniega, Victor. «Por el rumbo de La estación violenta. Lectura de sus lecturas críticas». América: Cahiers du Criccal, 6, (1989): 157-171.

Durán, Manuel. «La segunda época en la poesía de Octavio Paz». Actas del IV Congreso de la Asociación Internacional de Hispanistas, 1971. Recuperado de https://goo.gl/wohVsY.

Eco, Umberto. Los limites de la interpretación. Barcelona: Editorial Lumen, 1992.

Fernández Cozman, Camilo Rubén. Rodolfo Hinostroza y la poesía de los años sesenta. 2. ${ }^{a}$ ed. Lima: Universidad de Ciencias y Humanidades, 2009.

Fernández Cozman, Camilo Rubén. «El referente prehispánico y la poliacroasis en La estación violenta (1948-1957) de Octavio Paz». Tonos Digital, 1:29, (2015): 1-19. Recuperado de https://goo.gl/YDfQuq.

Fernández Cozman, Camilo Rubén. «El aporte de George Lakoff». Cuerpo de la metáfora (blog), 2018a. 
Recuperado de http://cuerpodelametafora.blogspot. com/2018/12/el-aporte-de-george-lakoff.html.

Fernández Cozman, Camilo Rubén. «Metáforas orientacionales y espacialización del sujeto en Una casa en la sombra, de Carlos López Degregori». Lexis, XLII:1, (2018b): 177-190.

Genette, Gérard. Ficción y dicción. Barcelona: Editorial Lumen, 1993.

Karam, Tani. «Piedra del Sol. Un acercamiento comunicológico a la vida-obra de Octavio Paz». Espéculo. Revista de Estudios Literarios, 29, 2005. Recuperado de https://goo.gl/mCHbMg.

LAKoff, George y Mark Johnson. Metáforas de la vida cotidiana. Madrid: Cátedra, 1995.

Lakoff, George y Mark Johnson. Philosophy in the Flesh, the embodied mind and its challenge to Western Thought. Nueva York: Basic Books, 1999.

Magis, Carlos Horacio. La poesía hermética de Octavio Paz. México: El Colegio de México, 1978.
Martínez Fernández, José Enrique. La intertextualidad literaria. Madrid: Cátedra, 2001.

Nubiola, Jaime. «El valor cognitivo de las metáforas». Cuadernos de Anuario Filosófico, 103, (2000): 74-84.

Paz, Octavio. La estación violenta. México, D. F.: Fondo de Cultura Económica, 1984.

Ricoevr, Paul. Tiempo y narración. El tiempo narrado. Tomo III. Madrid: Siglo Veintiuno Editores, 1996.

Ruiz Barrionuevo, Carmen. «La incesante búsqueda del lenguaje en la poesía de Octavio Paz». Revista de Filología de la Universidad de La Laguna, 3, (1984): 61-81.

TYLER, Joseph. «De lugares comunes a nociones distantes: la poesía de Octavio Paz». Actas del X Congreso de la Asociación Internacional de Hispanistas, 1989. Recuperado de https://goo.gl/r7faFV.

YáñEz, Adelso. «El enunciado y el contexto enunciativo: hacia la pragmática». Revista Comunicación, 11:2, (2000): 35-44. 